\title{
Proposta de modelo para planejamento de sistemas de informação para operação em ambientes de elevada turbulência organizacional - o caso do transporte rodoviário de produtos perigosos
}

\author{
Marne Lieggio Júnior \\ Mestre e doutorando em transportes pela Universidade de \\ Brasília (UnB), Brasília, DF - Brasil.
}

\section{Rogério Henrique Araújo Júnior}

Doutor em ciência da informação pela Universidade de Brasília (UnB) e professor. do Departamento de Ciência da Informação da Universidade de Brasília (UnB), Brasília, DF - Brasil.

\section{Sérgio Ronaldo Granemann}

Doutor em ciências econômicas pela Universite D'aix Marseille II e professor do Programa de Pós-Graduação em Transportes da Universidade de Brasília (UnB), Brasília, DF - Brasil.

\section{Resumo}

O objetivo deste trabalho consiste na proposição de um modelo para planejamento de sistemas de informação para operação em ambientes de elevada turbulência organizacional, citando-se como objeto de estudo a atividade de transporte rodoviário de produtos perigosos. A metodologia utilizada foi baseada na prospecção de estudos existentes acerca de construção de sistemas de informação, principalmente em ambientes de turbulência, agregando um modelo de gerenciamento de riscos aplicado à atividade de transporte específica. O modelo permite não apenas estruturar os sistemas de informação em ambientes turbulentos alinhados com o planejamento estratégico de órgãos e entidades envolvidos com o tema, como também considera o aspecto temporal dos eventos, as ações de cada ator em seu ambiente e o tipo de intervenção requerido.

\section{Palavras-chave}

Planejamento de sistemas de informação. Turbulência organizacional. Transporte rodoviário. Produtos perigosos. Gerenciamento de riscos.

Proposal of a model for the planning of information systems for use in environments of high organizational turbulence - the case of road transportation of dangerous products

\author{
Abstract \\ The objective of this work consists in proposing a \\ model for planning information systems for operation in \\ Ci. Inf., Brasília, DF, v. 39 n. 2, p.27-43, maio/ago., 2010
}

environments of high turbulence organization, citing as an object of study the activity of road transport of dangerous goods. The methodology was based on survey of existing studies on construction of information systems, especially in turbulent environments, adding a model of risk management applied to the activity of specific transport. The model structure allows not only information systems in turbulent environments aligned with the strategic planning of the public agency and entities involved with the issue, but also considers the temporal aspect of events, the actions of each actor in their environment and type of intervention required.

\section{Keywords}

Planning of information systems. Organizational turbulence. Road transport. Dangerous goods. Risk management.

\section{INTRODUÇÃO}

Ansoff e McDonnell (1993) afirmaram que a potencialidade da administração de uma organização, principalmente em ambientes turbulentos, é determinada por cinco fatores que interagem mutuamente: qualificação e mentalidade dos principais administradores; clima e cultura organizacional; estrutura de poder, sistemas e estrutura organizacional; capacidade da administração geral para o trabalho de gestão.

Com isso, a administração estratégica é uma abordagem sistemática da gestão de mudanças que envolve o planejamento das potencialidades, procurando respostas em tempo real mediante a administração de questões estratégicas e gestão da resistência durante a implantação da estratégia. A agressividade estratégica em ambientes de elevada turbulência está relacionada ao seu potencial de adaptação às mudanças, seja de forma reativa, 
antecipatória, inovadora ou criativa. O sucesso estratégico é alcançado pela otimização do potencial de desempenho, tendo como uma de suas premissas a necessidade de que a agressividade do comportamento da organização se equipare à turbulência do ambiente. Como exemplos de ambientes organizacionais turbulentos, demandantes de sistemas de informação adequados, podem citar-se desde salas de cirurgias hospitalares, passando pelas zonas de catástrofes ambientais, até o transporte rodoviário de produtos perigosos (TRPP).

O planejamento configura-se como um dos instrumentos gerenciais mais importantes no processo administrativo, sendo imprescindível, por exemplo, aos órgãos e entidades relacionados ao transporte rodoviário de produtos perigosos no momento de propor suas ações, que devem ser realizadas com o intuito de garantir a inserção segura e competitiva em seu mercado de atuação, no caso de empresas, ou uma atuação eficaz, eficiente e efetiva, no caso de órgãos reguladores, fiscalizadores e de assistência emergencial.

Os sistemas de informação, por sua vez, representam para as organizações o requisito central aos processos de estruturação, controle e gestão de grande quantidade de dados e papéis que adquirem valor nos processos decisórios, desde que organizados e disponibilizados em uma estrutura que contemple a coleta de dados de entrada, processamento dos dados e informações de saída.

Oplanejamento de sistemas de informação relacionados ao turbulento ambiente em que se processa a atividade de transporte de produtos perigosos permite estabelecer o futuro desenho dos modelos de gestão da informação que subsidiarão órgãos e entidades envolvidos com a questão em seu desenvolvimento. Portanto, é uma atividade estratégica, associada à missão e aos objetivos organizacionais.

Embora o planejamento da prevenção de ocorrências indesejáveis com produtos perigosos (tais como acidentes) ocorra nas várias fases do processo - produção, transporte, transformações, utilização e disposição final - os maiores riscos, segundo Ramos (1997), encontram-se na etapa do transporte.

Durante o transporte, a carga fica exposta a situações de riscos dificilmente evitáveis, devido a fatores adversos, tais como acidentes com outros veículos, condições de transporte e de trânsito, traçado da pista e de sua manutenção, habilidade e condição do motorista e ausência ou deficiência de informações específicas sobre o produto transportado.

No Brasil, o modo rodoviário lidera a movimentação de produtos perigosos e os controles de riscos aplicáveis ao transporte requerem a ação de vários atores - governo, empresários e sociedade - os quais detêm níveis de poder e atuação diferenciados, para efetivá-los. Essas ações podem ser pessoais, gerenciais, técnicas, legais e políticas; devem visar à segurança e à eficiência do transporte; e demandam grande fluxo de informações e sistemas adequados para processá-las e disponibilizá-las no momento requerido.

Nesse contexto, o objetivo deste artigo é a proposição de um modelo para planejamento de sistemas de informação relacionados ao transporte rodoviário de produtos perigosos, de modo que o mesmo possa ser utilizado como uma ferramenta de redução de riscos de ocorrências indesejáveis na movimentação desse tipo de carga por órgãos e entidades relacionados à temática.

Este artigo está dividido em seis itens, incluindo esta introdução. No item 2, é apresentada uma visão do planejamento de sistemas de informação, abrangendo o contexto do planejamento e a concepção de um sistema informacional em ambientes turbulentos. No item 3, é tratado o transporte rodoviário de produtos perigosos, o gerenciamento de riscos e as necessidades de informação. No item 4, abordam-se os modelos de gerenciamento de riscos aplicados ao TRPP. Passa-se ao item 5, em que se propõe o modelo para planejamento de sistemas de informação em ambientes de elevada turbulência, relacionando-o ao 
Proposta de modelo para planejamento de sistemas de informação para operação em ambientes de elevada turbulência...

caso do TRPP, e, finalmente, no item 6 , encontramse as conclusões e recomendações finais.

\section{PLANEJAMENTO DE SISTEMAS DE INFORMAÇÃO}

Este item será discernido com o entendimento do contexto do planejamento e a concepção dos sistemas de informação.

\section{Entendimento do contexto do planejamento}

Segundo Sanches (1997), o termo planejamento significa ato ou efeito de planejar. Portanto, se planejar é conhecer a realidade presente e formular imagens de uma realidade desejável e viável para o futuro, bem como articular as providências que viabilizem a materialização de tal realidade, pode-se definir planejamento como o conjunto de ações integradas, situadas no tempo e no espaço, orientadas para a solução de problemas (existentes ou antecipados) ou implementação de mudanças com o apropriado emprego dos recursos.

O planejamento é um processo articulado que envolve a definição de objetivos e o equacionamento dos meios que permitam atingi-los. Requer, portanto, previsões confiáveis fundadas em adequado diagnóstico da realidade atual, da evolução histórica dos fenômenos e das tendências existentes, o envolvimento dos escalões superiores que garantirão implementabilidade às decisões e legitimação pelo ambiente.

Segundo Bio (1989), o planejamento se orienta para a definição das ações da empresa no meio ambiente com vistas a orientá-la para a posição futura desejada. Envolve, portanto, a realização de levantamentos e as avaliações de situações com vistas à definição da estratégia da organização para fazer frente aos problemas estruturais e aos desafios percebidos no futuro, bem como para a fixação de objetivos e a seleção dos instrumentos de intervenção sobre o ambiente.

Similar é a percepção de Davis (1974), que ao tecer considerações sobre os três níveis de planejamento referidos na literatura (estratégico, tático e operacional), assevera que o planejamento lida com considerações de longo prazo. Por exemplo, as decisões a serem tomadas com relação aos negócios em que a organização deva entrar, os mercados para os quais se deva voltar e a composição de sua pauta de produtos.

Segundo Araújo Jr. e Alvares (2007), atualmente, planejamento e estratégia são considerados um modelo único de gestão chamado administração estratégica. A partir da década de 1980, a formulação e a operacionalização da estratégia passaram a ser o paradigma do modelo de gestão com o foco na análise competitiva para o correto gerenciamento de mudanças. Outro fator importante nesse modelo de gestão é a necessária difusão interna da estratégia corporativa e, com isso, transformar funcionários em colaboradores.

Técnicas como a de Cenários, Análise SWOT e Benchmarking continuam sendo amplamente utilizadas para o diagnóstico estratégico. De mesma monta, previsões econométricas ou matrizes de análise de portifólios de produtos e serviços, típicas do planejamento de longo prazo, ainda têm sua utilidade em tempos de administração estratégica.

Para Oliveira (1999), o planejamento possui características suficientes para obter importância estratégica em qualquer empreendimento organizacional. Dentre elas, elencam-se:

a) está ligado ao desenvolvimento futuro das organizações, antecipando-se aos acontecimentos;

b) promove a tomada de decisão de forma ordenada;

c) preocupa-se com as mudanças do meio ambiente externo, bem como com a correta utilização dos recursos internos disponíveis;

d) identifica necessidades de mudança na postura organizacional, além de promover um processo interno de mudanças; e

e) preocupar-se com a cultura organizacional. 
A figura 1 ilustra o processo de planejamento proposto por Oliveira (2001).

O processo inicia-se a partir da visão. Algumas vezes, irrealista quanto aos destinos da empresa e submetida a uma avaliação racional e criteriosa das oportunidades e ameaças. As oportunidades são em termos de mercados a explorar e recursos a aproveitar. As ameaças são aquelas que prejudicarão a empresa e suas oportunidades.

Considerando-se a realidade da empresa e de seus concorrentes, com seus pontos fortes, fracos ou neutros, traça-se o horizonte estabelecido para a missão, que deve conduzir à escolha de propósitos. A partir de detalhes de cenários, respeitando a postura estratégica, que possibilita o estabelecimento de macroestratégias e macropolíticas, que orientarão a formalização de objetivos gerais e funcionais mais realistas que as expectativas e os desejos, estabelecem-se os desafios e as metas.

Quantificados os desafios e as metas, eles permitirão o estabelecimento, em nível funcional, de estratégias e políticas capazes de tirar proveito dos pontos fortes e oportunidades, além de evitar ou eliminar os pontos fracos e ameaças da empresa.

Para tanto, são delineados os projetos e os planos de ação destinados a orientar a operacionalização do plano estratégico por meio de um orçamento econômico-financeiro.

Chaín (2000) propõe um processo de planejamento de quatro etapas: filosófica, analítica, elaboração do plano e avaliação e controle.

A etapa filosófica consiste na declaração de princípios e valores que explicitam as opções da organização ao construir o planejamento. Também inclui a definição da missão que fundamenta e impulsiona a criatividade de uma organização e as macropolíticas que surgem como uma consequência lógica.

A etapa analítica considera a precisão da realidade específica de atuação das organizações mediante a análise dos seus ambientes interno e externo. Este conhecimento é imprescindível para situar a atividade de gestão da informação na realidade concreta dos métodos e processos organizacionais.

A análise interna desta etapa corresponde à avaliação das carências, fraquezas e forças. As carências são os valores, recursos ou qualidades necessárias ao alcance dos objetivos. Como exemplo, cita-se uma empresa de TRPP que não possui um serviço de informação de apoio às suas atividades. As fraquezas são valores negativos presentes em todas as empresas que se colocam como obstáculo ao seu desenvolvimento. Como exemplo, mencionase uma empresa de TRPP que tenha um serviço de informação sustentado por profissionais não especializados no manejo da informação. As forças são os valores que a organização possui e que servem para alcançar os objetivos preestabelecidos. Uma

\section{FIGURA 1}

\section{Processo de planejamento.}

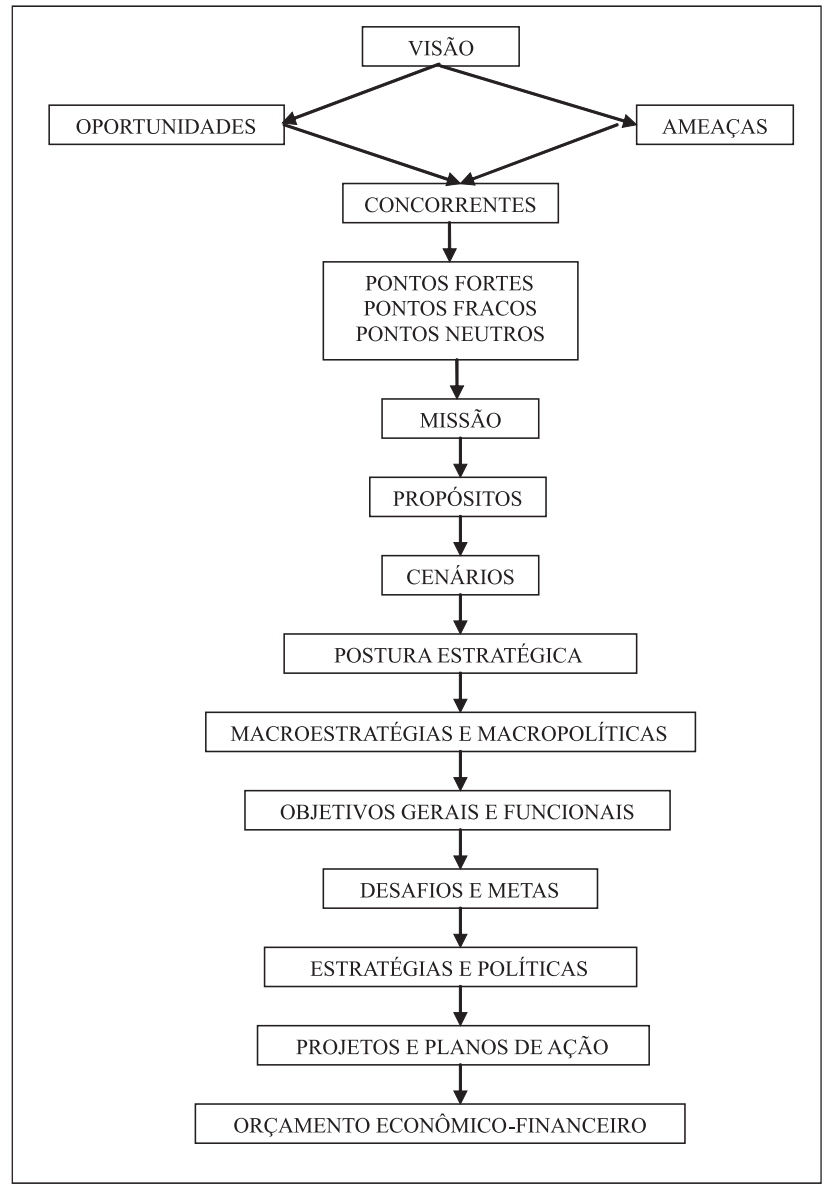

Fonte: adaptado de Oliveira (2001). 
Proposta de modelo para planejamento de sistemas de informação para operação em ambientes de elevada turbulência...

força informacional em uma empresa de TRPP é a existência de um sistema de rastreamento veicular.

A análise externa da etapa analítica associa-se à avaliação das oportunidades, problemas e ameaças. As oportunidades são forças ambientais que podem favorecer, por meio de ações, o desenvolvimento da organização. Uma informação sobre a necessidade concreta de desenho de nova embalagem para determinado produto perigoso é um exemplo de oportunidade. As ameaças são situações de risco que paralisam ou interrompem definitivamente o fluxo informacional, como a inoperância de um sistema de roteirização de veículos.

Na etapa de elaboração do plano, ocorre a sinergia entre as etapas anteriores, que deve ser a motivação inicial para a formulação de um plano diretor de desenvolvimento do sistema de informação, que deve possuir objetivos, estratégias e planos de ação.

A etapa de avaliação e controle consiste na execução de todas as atividades propostas, bem como o seu controle e a sua retroalimentação. A finalidade desta etapa está em corrigir o desenrolar das ações planejadas conforme as exigências contidas nos objetivos preestabelecidos.

\section{Entendimento da concepção dos sistemas de informação}

Na lição de Araújo Jr. e Alvares (2007), a concepção de um sistema de informação deve estar baseada no pressuposto de que a informação é um recurso estratégico à gestão e deve desempenhar papel especialmente importante no desenvolvimento de esforços para criar e manter a diferenciação de produtos e serviços.

A relação estreita que existe entre os sistemas de informação e o processo decisório justifica o propósito destes sistemas. Eles devem ter sua missão e seus objetivos calcados na missão e nos objetivos da organização que os hospeda. Tal prerrogativa é essencial para que os resultados apresentados estejam em conformidade com as necessidades de informação de todos os componentes dentro das organizações.
Para que os sistemas de informação estejam voltados às necessidades informacionais de seus usuários, além da missão e dos objetivos em sintonia, deve-se atentar aos requisitos da qualidade da informação.

Para O’Brien (2000) apud Araújo Jr. e Alvares (2007), os requisitos da qualidade da informação são classificados em relação ao tempo, ao conteúdo e à forma, como segue:

a) Em relação ao tempo:

- disponibilidade: a informação deve ser disponibilizada quando for necessária;

- atualização: a informação necessita estar atualizada quando for demandada;

- frequência: a informação deve ser disponibilizada sempre que requerida; e

- período: a informação deve ser disponibilizada em relação ao passado e ao presente, além de ser proativa no atendimento às necessidades informacionais.

b) Em relação ao conteúdo:

- precisão: a informação não deve conter erros e estar em conformidade com as necessidades de informação dos usuários;

- concisão: toda a informação necessária deve ser disponibilizada;

- amplitude: a informação pode ser específica ou geral, dependendo da demanda; e

- performance: a informação pode ter seu conteúdo voltado para o relato da performance de um sistema.

c) Em relação à forma:

- clareza: a informação deve ser disponibilizada de forma clara e de fácil compreensão;

- completeza: a informação deve ser disponibilizada na íntegra ou sintetizada, conforme a demanda;

- formato: a informação deve ser disponibilizada em um formato que a torne inteligível e esteja de acordo com os requisitos de acesso dos usuários. 
Para Furlan (1991), a concepção de sistemas de informação é a etapa inicial em que se estabelecem os propósitos básicos para que se possam implantar, posteriormente, sistemas computadorizados estáveis e de apoio à tomada de decisões. Como tal, devem ser elaborados de modo a propiciar os elementos necessários para suportar os negócios da organização, atingir seus objetivos e atender às necessidades de informação de sua alta administração. Em termos mais específicos, a concepção de sistemas de informação pode ser caracterizada como o conjunto de ações integradas com vistas à:

a) determinação do usuário do sistema, dos elementos necessários para o apoio às suas decisões e das suas preferências em termos de formatação dos dados;

b) identificação das áreas de interesse estratégico para a atuação do decisor e dos elementos importantes em cada uma destas;

c) determinação do âmbito operacional da organização e dos seus objetivos (de curto, médio e longos prazos);

d) identificação de concorrentes, opositores e adversários;

e) realização do diagnóstico da situação dos sistemas de informação disponíveis ou mobilizáveis como fontes de dados e informações;

f) sistematização de estrutura que satisfaça às necessidades e que seja viável no prazo disponível para a sua operacionalização;

g) fixação de objetivos e de metas para o sistema e para sua implantação;

h) capacitação dos recursos humanos envolvidos na operacionalização do sistema;

i) determinação dos recursos necessários e dos responsáveis pelo desenvolvimento e implantação do sistema; e

j) definição dos requisitos mínimos a serem atendidos nas simulações e testes-piloto.
Sob o ponto de vista de sistemas de informações logísticas empregados no TRPP, Bowersox e Closs (2001) afirmam a necessidade da funcionalidade da informação. Tais sistemas são a interligação das atividades logísticas para criar um processo integrado. A integração baseia-se em quatro níveis de funcionalidade: sistemas transacionais, controle gerencial, análise de decisão e planejamento estratégico (figura 2, a seguir).

O nível mais básico, que compreende o sistema transacional, inicia e registra atividades logísticas individuais. O segundo nível, controle gerencial, concentra-se na avaliação de desempenho e na exploração de relatórios. O terceiro nível, análise de decisão, enfatiza o uso da informação no processo de tomada de decisão para auxiliar os executivos a identificar, avaliar e comparar alternativas logísticas táticas e estratégicas. O nível final, planejamento estratégico, concentra-se em informações destinadas a desenvolver e aperfeiçoar a estratégia logística.

Segundo Certo e Peter (1993), durante a gestão dos sistemas de informação, é imprescindível a opção por modelos de exames ambientais adequados, uma vez que a adoção de um ou outro modelo pode revelar características qualitativas de reatividade e/ ou proatividade dos sistemas no atendimento das demandas informacionais.

Atendendo às premissas apresentadas, Araújo Jr. e Alvares (2007) propuseram um modelo para o planejamento de sistemas de informação, que será utilizado como parte do modelo proposto específico ao caso dos órgãos e entidades associados ao TRPP.

A figura 3, a seguir, ilustra o modelo de Araújo Jr. e Alvares (2007), que agrega três princípios essenciais, a saber:

a) adaptação da missão e dos objetivos do sistema à missão e objetivos da organização em que está inserido: por meio de avaliações periódicas das estatísticas de uso e da satisfação das necessidades de informação dos usuários do sistema, coleta sistemática de dados para a atualização dos 
Proposta de modelo para planejamento de sistemas de informação para operação em ambientes de elevada turbulência...

FIGURA 2

Funcionalidade requerida de um sistema de informação logístico no TRPP.

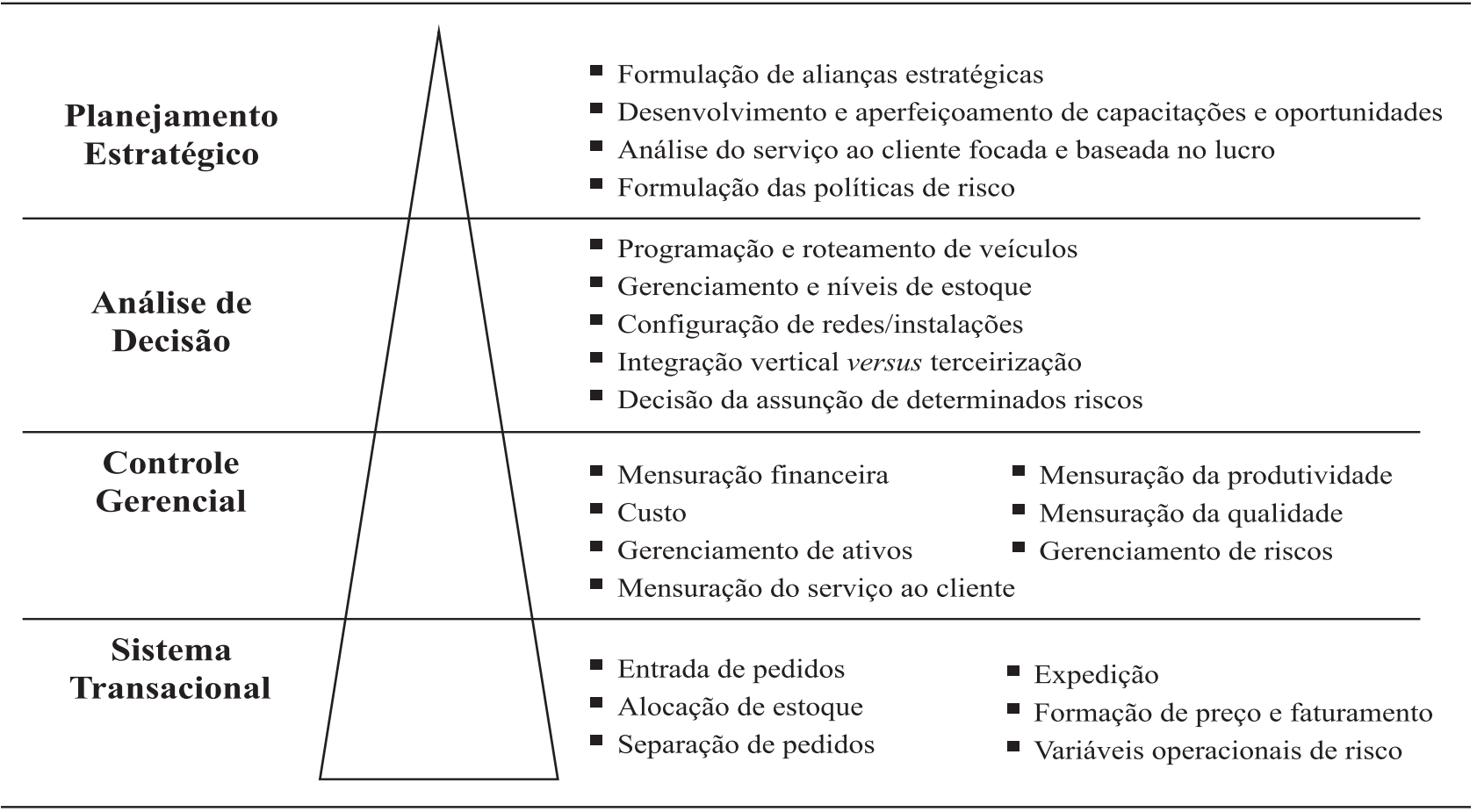

Fonte: adaptado de Bowersox e Closs (2001).

FIGURA 3

Modelo de Araújo Jr. e Alvares (2007) para planejamento de sistemas de informação.

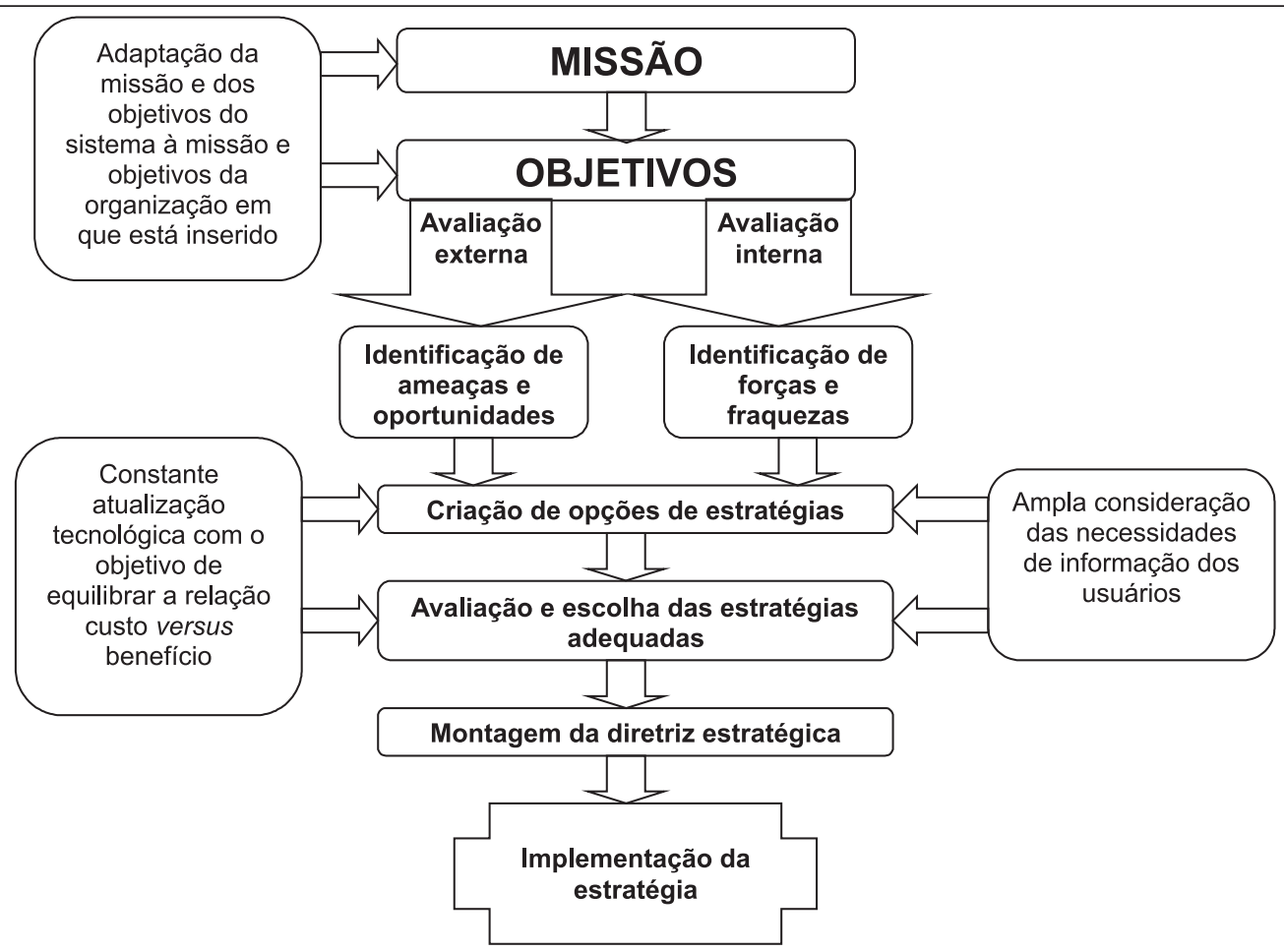

Fonte: Araújo Jr. e Alvares (2007).

Ci. Inf., Brasília, DF, v. 39 n. 2, p.27-43, maio/ago., 2010 
perfis de consumo de informações dos usuários, correção do modelo de gestão estratégica proposto para hospedar o sistema de informação da organização;

b) ampla consideração das necessidades de informação dos usuários: por meio de levantamentos minuciosos dos perfis de consumo da informação das organizações e de seus colaboradores, estudo de suas necessidades de informação e a formatação de produtos e serviços a serem disponibilizados no âmbito da gestão da informação;

c) constante atualização tecnológica com o objetivo de equilibrar a relação custo versus benefício: por intermédio do estabelecimento de processos de benchmarking e de monitoramento tecnológico em uma área de negócios específica, monitoramento e mapeamento sistemático do "estado da arte" do desenvolvimento de tecnologias da informação e comunicação, com vistas à promoção de atualizações nos instrumentos de coleta dos dados, nas concepções e ferramentas do processamento da informação e nos formatos de saída das informações a serem distribuídas e disseminadas entre os usuários do sistema.

\section{Sistemas de informação e turbulências organizacionais}

Ansoff (1978) abordou a escalada da turbulência do ambiente organizacional no século XX, afirmando que as firmas se encontram na incômoda situação em que o tempo disponível se tornou mais curto e o tempo necessário para uma resposta eficaz se tornou mais longo.

Segundo Ansoff e McDonnell (1993), a velocidade com que novos produtos ou serviços ingressam no mercado tem acelerado o processo de mudança dentro das organizações, refletindo nos sistemas de informação. Tal processo provoca, dentre outras consequências, a dificuldade de antecipar a mudança para planejar com antecedência uma resposta oportuna, a necessidade de maior velocidade na implantação da resposta e a necessidade de flexibilidade em apresentar resposta oportuna diante do inesperado. Diante da crescente turbulência ambiental em termos de imprevisibilidade e complexidade, cada empresa precisa diagnosticar sua configuração própria de desafios, ameaças e oportunidades futuros, como também, projetar e implantar sua própria resposta a esses desafios.

Nesse contexto, incluem-se, também, ambientes como salas de emergências hospitalares, organizações e sistemas de ação em situações de desastres naturais, acidentes de grandes proporções, perturbações intensas na ordem sociopolítico-econômica e o ambiente de prestação de serviços de transporte rodoviário de produtos perigosos. Em regra, as questões relacionadas com tais ambientes turbulentos dependem de alto número de variáveis que se alteram no tempo com elevadas taxas. E os riscos e as incertezas associados aos processos decisionais em tais condições são de tal monta, que demandam características especiais dos sistemas de informação de apoio à decisão (ANSOFF, 1978).

De acordo com Ansoff e McDonnell (1993), a turbulência ambiental é uma medida composta da variabilidade e da previsibilidade do ambiente da organização. A variabilidade se caracteriza pela novidade relativa aos desafios enfrentados pela empresa no ambiente e pela complexidade do seu ambiente. A previsibilidade trata da relação entre a velocidade com a qual os desafios evoluem no ambiente e a velocidade de reação da empresa, ou seja, a rapidez da mudança. A lista dos atributos desses autores considera para o diagnóstico do nível esperado de turbulência contempla: diferenciação da estratégia de marketing, frequência de novas estratégias de marketing, pressão dos clientes, demanda/capacidade da indústria, pressão do governo (principalmente por meio de marcos regulatórios), pressão dos ecologistas, diferenciação dos produtos, frequência de novos produtos na indústria, ciclos da vida de produtos, velocidade de alteração de tecnologia, diversidade de tecnologias concorrentes, fatores críticos de sucesso para inovação e fatores críticos de sucesso em marketing. 
Proposta de modelo para planejamento de sistemas de informação para operação em ambientes de elevada turbulência...

Na tabela 1, são demonstradas a escala de turbulência ambiental e a correspondência entre agressividade, capacidade de reação e turbulência, como ferramentas aplicáveis ao diagnóstico estratégico, na visão de Ansoff e McDonnell (1993).

Ansoff e McDonnell (1993) também apresentam, em escala de 1 a 5, o nível de turbulência esperado no ambiente, que varia de repetitiva a surpreendente. O significado desses níveis é apresentado na tabela 2.
TRANSPORTE RODOVIÁRIO DE PRO DUTOS PER I G S O S, GERENCIAMENTO DE RISCOS E NECESSIDADES DE INFORMAÇÃO

O gerenciamento das variáveis relacionadas ao risco no TRPP demanda intensos fluxos de informações, sendo indispensável o planejamento de adequados sistemas de informação para processá-las e disponibilizá-las aos vários atores relacionados à questão.

\section{TABELA 1}

Escala de turbulência ambiental

\begin{tabular}{c|c|c|c|c|c}
\hline $\begin{array}{c}\text { Turbulência } \\
\text { ambiental }\end{array}$ & Repetitiva & $\begin{array}{c}\text { Em } \\
\text { expansão }\end{array}$ & $\begin{array}{c}\text { Em } \\
\text { Mudança }\end{array}$ & Descontínua & Surpreendente \\
\hline $\begin{array}{c}\text { Complexidade } \\
\text { Familiaridade dos } \\
\text { eventos }\end{array}$ & $\begin{array}{c}\text { econômica } \\
\text { nacional }\end{array}$ & + & $\begin{array}{c}\text { tecnologia } \\
\text { regional }\end{array}$ & + & $\begin{array}{c}\text { fociopolítica } \\
\text { mundial }\end{array}$ \\
\hline $\begin{array}{c}\text { Rapidiares da } \\
\text { mudança }\end{array}$ & $\begin{array}{c}\text { mais lenta } \\
\text { do que a } \\
\text { reação }\end{array}$ & extrapoláveis & $\begin{array}{c}\text { compares e } \\
\text { reação }\end{array}$ & $\begin{array}{c}\text { novos e } \\
\text { descontínuos }\end{array}$ \\
\hline $\begin{array}{c}\text { Visibilidade do } \\
\text { futuro }\end{array}$ & repetitivo & previsível & predisível & $\begin{array}{c}\text { parcialmente } \\
\text { predisível }\end{array}$ & $\begin{array}{c}\text { mais rápida do } \\
\text { que a reação } \\
\text { imprevisáseis }\end{array}$ \\
\hline $\begin{array}{c}\text { Nível de } \\
\text { turbulência }\end{array}$ & 1 & 2 & 3 & 4 & 5 \\
\hline
\end{tabular}

Fonte: Adaptado de Ansoff e McDonnell (1993).

TABELA 2

Escala de identificação de alinhamento estratégico

\begin{tabular}{|c|c|c|c|c|c|}
\hline $\begin{array}{c}\text { Turbulência } \\
\text { Ambiental }\end{array}$ & Repetitiva & Crescente & Mutável & Descontínua & Inesperada \\
\hline $\begin{array}{l}\text { Agressividade } \\
\text { estratégica }\end{array}$ & $\begin{array}{l}\text { Estável } \\
\text { Baseada em } \\
\text { precedentes }\end{array}$ & $\begin{array}{l}\text { Reativa } \\
\text { Gradativa com } \\
\text { base na } \\
\text { experiência }\end{array}$ & $\begin{array}{l}\text { Antecipatória } \\
\text { Gradativa com } \\
\text { base na } \\
\text { extrapolação }\end{array}$ & $\begin{array}{l}\text { Empreendedora } \\
\text { Descontínua com } \\
\text { base no futuro } \\
\text { esperado }\end{array}$ & $\begin{array}{l}\text { Criativa } \\
\text { Descontínua com } \\
\text { base na criatividade }\end{array}$ \\
\hline $\begin{array}{l}\text { Capacidade de } \\
\text { reação da } \\
\text { potencialidade }\end{array}$ & $\begin{array}{l}\text { De manutenção } \\
\text { Motivada por } \\
\text { procedentes } \\
\text { Reprime a } \\
\text { mudança }\end{array}$ & 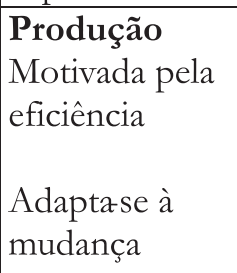 & $\begin{array}{l}\text { Marketing } \\
\text { Motivada pelo } \\
\text { mercado } \\
\text { Busca mudança } \\
\text { conhecida }\end{array}$ & $\begin{array}{l}\text { Estratégia } \\
\text { Motivada pelo } \\
\text { ambiente } \\
\text { Busca mudança } \\
\text { conhecida }\end{array}$ & $\begin{array}{l}\text { Flexível } \\
\text { Procura criar } \\
\text { ambientes } \\
\text { Busca criatividade }\end{array}$ \\
\hline Nível de turbulência & 1 & 2 & 3 & 4 & 5 \\
\hline
\end{tabular}

Fonte: Adaptado de Ansoff e McDonnell (1993). 
De acordo com a Resolução ANT'T no 420/2004 (ANTT, 2004), que aprova as Instruções Complementares ao Regulamento do Transporte Terrestre de Produtos Perigosos, é denominado produto perigoso "toda substância ou artigo encontrado na natureza ou produzido por qualquer processo que, por suas características físicoquímicas, represente risco para saúde das pessoas, para a segurança pública ou para o meio ambiente".

A inexistência ou insuficiência de informações no TRPP pode acarretar graves acidentes que implicam, em geral, riscos à saúde humana, à gestão do tráfego, à infraestrutura viária e à segurança pública, podendo causar efeitos danosos à comunidade e à biota local.

Lieggio Júnior (2008) mostra que a movimentação da produção dos setores químico, petroquímico e de refino de petróleo, entre outros, é feita na sua maioria por rodovias. Por conseguinte, essa atividade lidera as estatísticas de sinistros ambientais, com 2.597 acidentes, ou seja, 38,8\% do total de acidentes ocorridos no Estado de São Paulo entre 1978 e 2006 (CETESB, 2008). Cabe destacar que o transporte rodoviário foi responsável por $53,7 \%$ do total dos atendimentos emergenciais ocorridos em 2007 no Estado de São Paulo.

Considerando-se apenas uma visão geral da cadeia logística de produtos perigosos, pode-se verificar quão intenso é o fluxo de informações: gerenciamento de pedidos; processamento de pedidos; gerenciamento de estoques; roteirização; operações e distribuição; transporte e expedição; monitoramento de entregas; suprimento (BALLOU, 2006).

Descendo à necessidade de informações específicas relacionadas ao gerenciamento de riscos no transporte, salienta-se, como exemplo, a figura do embarcador. Sua necessidade informacional é tamanha que pode ser compreendida, de início, no estágio de planejamento de expedição, em que deve se atentar às exigências legais de transporte (classificação do produto perigoso transportado; cuidados referentes à embalagem; marcação e rotulagem de volumes; identificação das unidades de transporte e de carga; documentação; prescrições aplicáveis a veículos e equipamentos do transporte rodoviário; requisitos de quantidade limitada e provisões especiais, quando aplicáveis).

No estágio de operação ou produção do transporte, o embarcador não deve descurar, em hipótese alguma, de informações relacionadas ao risco, tais como: monitoramentos de programa de manutenção de unidades e equipamentos de transporte; de programa de higiene e saúde ocupacional de seus colaboradores; de programa de qualidade ambiental; de programa de qualidade dos serviços; de sistema de rastreamento veicular; da integridade do produto; de índice de acidentes; entre outras.

Além disso, no caso de ausência ou deficiência das informações legais requeridas, tanto na documentação de transporte ou das informações constantes nas unidades e equipamentos de transporte, os embarcadores e os transportadores podem ser penalizados com a aplicação de multas pelos órgãos fiscalizadores. Ressalta-se, ainda, o fato de que a legislação do TRPP se inter-relaciona com a legislação ambiental, positivando os princípios da corresponsabilidade e do pagador-poluidor.

$\mathrm{Na}$ fase de assistência emergencial, Poffo et al. (2005) preconizam que o fluxo informacional se faz presente em todas as etapas das operações de resposta. Ou seja, na informação do sinistro; no acionamento das equipes de combate; na avaliação do cenário acidental; durante o processo de atendimento, na avaliação das consequências (danos à saúde e segurança do homem, impactos ecológicos e socioeconômicos); na avaliação e no encerramento dos trabalhos; no repasse de informações técnicas à mídia; no contato com a comunidade.

Em seus estudos, Real (2000) chega a propor o Sistema de Informações sobre Produtos Perigosos (SIPP) para dar suporte aos atendimentos emergenciais assistidos (AEA). Nesse SIPP, há um banco de dados que concentra, entre outros, uma matriz de avaliação de riscos, fichas de emergências de produtos perigosos, cadastro de informações para 
Proposta de modelo para planejamento de sistemas de informação para operação em ambientes de elevada turbulência...

contato ou acesso a organizações externas à rodovia e cadastro de incidentes.

O item a seguir apresenta alguns modelos de gerenciamento de riscos mais utilizados no TRPP e os correspondentes parâmetros que necessitam trafegar em um sistema de informação.

\section{MODELOS DE GERENCIAMENTO DE RISCOS APLICADOS AO TRPP}

Segundo Hartman (2003), as metodologias mais usuais de análise de riscos decorrentes do transporte rodoviário de produtos perigosos são baseadas na interação entre a probabilidade de acidente e suas consequências.

Outros autores, como Rhyne (1994), Harwood et al. (1990), Scalon e Cantilli (1985) e Pijawka (1985), trabalharam com a avaliação de rotas de menor risco no transporte de produtos perigosos tomando como base a mesma premissa.

Os estudos de Verter e Kara (2001), Gheorghe (2006) e Porath et al. (2005) podem ser destacados na abordagem de transporte de produtos perigosos, com ênfase no uso de modelagens multicritérios, enfocando, sobretudo, parâmetros de tráfego com o apoio de ferramentas do tipo GIS (Geographic Information System).

De forma geral, tais estudos fundamentam-se nos seguintes parâmetros, que devem ser monitorados por adequados sistemas de informação: (a) vulnerabilidade do ambiente rodoviário e de seu entorno, englobando fatores de conflitos potenciais com a população lindeira, com os recursos naturais do entorno, com a geometria e a operação da rodovia e com o suporte emergencial local, que afetam sobremaneira a gestão do tráfego na via; (b) periculosidade das substâncias determinada para cada segmento rodoviário em função das características físico-químicas e das quantidades transportadas de cada tipo de produto; (c) frequência desse transporte em termos do número de viagens realizadas por mês; e (d) probabilidade de um tanque apresentar vazamento, dado que houve acidente com a unidade de transporte ou de carga.

Ci. Inf., Brasília, DF, v. 39 n. 2, p.27-43, maio/ago., 2010
Complementando esses estudos, Andersson e Menckel (1995) desenvolveram um modelo para gerenciamento de riscos que engloba as diversas fases de transporte, as atividades de prevenção, os atores envolvidos e as necessidades de informação. Por ser de fácil aplicação pelos diversos atores envolvidos com a questão, tal modelo foi utilizado para compor o modelo final de planejamento de sistemas de informação como fator redutor de acidentes no TRPP.

\section{O modelo de prevenção de acidentes de Andersson e Menckel (1995)}

O modelo de Andersson e Menckel (1995) é abrangente, qualitativo e incorpora as dimensões, os parâmetros identificados como relevantes à prevenção de acidentes e seus danos e as necessidades informacionais do TRPP. A figura 4, a seguir, ilustra o modelo sintético de prevenção de acidentes, seus danos e níveis de atuação dos atores.

Na concepção de Real (2000), tal modelo incorpora quatro dimensões básicas que devem ser consideradas para o estabelecimento de estratégias de prevenção e mitigação e que se relacionam com o fluxo informacional:

- Curso temporal dos eventos: representado pelo eixo das abscissas, indica o fluxo informacional de acordo com as fases temporais relativas aos eventos acidentais e às medidas de prevenção aplicáveis, desde os estágios que os antecedem pré-risco e risco, até os que os sucedem - o acidente e seus danos.

- Niveis: representados pelo eixo das ordenadas, indica o fluxo informacional em relação aos níveis em que as medidas podem ser implementadas, tendo em vista o plano de atuação e o poder de intervenção dos atores no processo de controle, prevenção e mitigação, bem como o sentido de sua abordagem.

- Abordagem das intervenções: as setas indicam o sentido do fluxo informacional e da aplicação das intervenções, que podem ser tecnocrática (seta para cima) ou democrática (seta para baixo). A abordagem 
FIGURA 4

Modelo sintético de prevenção de acidentes, seus danos e níveis de atuação dos atores envolvidos no gerenciamento de risco no TRPP

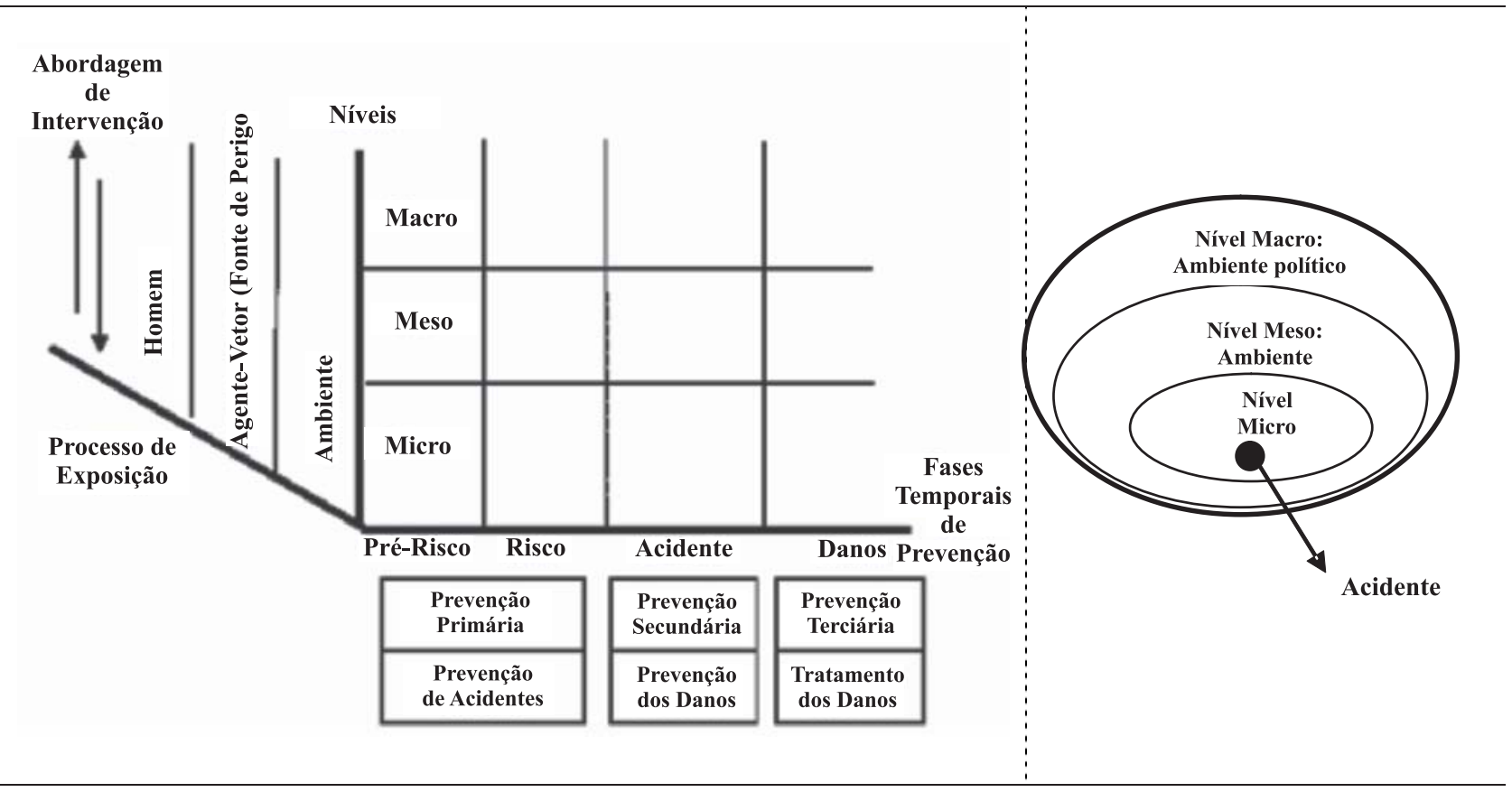

Fonte: adaptado de Andersson e Menckel (1995).

tecnocrática é aquela em que o Estado, por meio de seus instrumentos regulatórios e coercitivos, inicializa ou comanda o processo de prevenção. Já a democrática origina-se do público e envolve as comunidades sob risco no processo preventivo.

- Processo de exposição: representado pelo eixo das cotas, é a terceira dimensão do modelo e contempla o fluxo informacional, indicando o processo por meio do qual o agente agressor e/ou a fonte de perigo hostilizam o homem e o meio ambiente.

Em relação ao nível de atuação dos atores envolvidos no gerenciamento de risco no TRPP, Real (2000) preceitua que estão situados nos níveis macro, meso e micro.

No nível macro, encontram-se as necessidades informacionais concernentes aos governos federal e aos estaduais, cujo principal interesse é a adoção de políticas que favoreçam a vitalidade econômica das sociedades industrializadas e a redução dos riscos de incidentes ao público e ao meio ambiente.

No nível meso, circulam as informações referentes às instituições responsáveis pela fabricação dos produtos perigosos e pela operação do transporte: as empresas produtoras, expedidoras e transportadoras dos produtos, bem como a empresa seguradora e a concessionária rodoviária, caso o trecho em estudo esteja sob o regime de concessão. As políticas internas adotadas nessas corporações normalmente geram conflitos entre a economia e a segurança para o aludido tipo de transporte. Ainda que, legalmente, as responsabilidades quanto à segurança durante o transporte rodoviário recaiam sobre as empresas diretamente envolvidas com o embarque e o transporte de produtos perigosos, não há como negar que as condições físicas da rodovia, que devem ser amplamente veiculadas, assim como os recursos nela disponíveis para realizar o atendimento emergencial, também contribuem para a redução dos riscos de acidentes ambientais durante a operação de transporte. 
Proposta de modelo para planejamento de sistemas de informação para operação em ambientes de elevada turbulência...

No nível micro reside o ambiente rodoviário, o qual congrega as informações atinentes à rodovia, sua infraestrutura e obras de arte, usuários, empregados, comunidades e as biotas lindeiras, todos sujeitos aos riscos de danos físicos e materiais, em caso de acidentes rodoviários com produtos perigosos. As prefeituras locais, associações comunitárias, órgãos governamentais de apoio local, como Polícia Rodoviária Federal ou Estadual, de meio ambiente, Corpo de Bombeiros, Defesa Civil e hospitais, assim como as bases operacionais da concessionária rodoviária, têm seus interesses norteados à proteção dos integrantes desse ambiente rodoviário e o planejamento de um tráfego informacional eficaz e eficiente é imprescindível. E somente as intervenções praticadas nesse nível, ou seja, no local da ocorrência do acidente, podem mitigar seus danos.

\section{PROPOSIÇÃO DO MODELO PARA PLANEJAMENTO DE SISTEMAS DE INFORMAÇÃO EM AMBIENTES DE ELEVADA TURBULÊNCIA ORGANIZACIONAL - O CASO DO TRANSPORTE RODOVIÁRIO DE PRODUTOS PERIGOSOS}

O modelo proposto congrega os três princípios essenciais do modelo para planejamento de sistemas de informação de Araújo Jr. e Alvares (2007) adaptação da missão e dos objetivos do sistema à missão e objetivos da organização em ambiente turbulento em que está inserido; ampla consideração das necessidades de informação dos usuários; e constante atualização tecnológica com o objetivo de equilibrar a relação custo versus benefício, bem como as quatro dimensões básicas do modelo de prevenção de acidentes de Andersson e Menckel (1995) - curso temporal dos eventos, níveis de atuação dos atores, abordagem das intervenções e processo de exposição (figura 5 , a seguir).

O modelo permite não apenas estruturar os sistemas de informação alinhados com o planejamento estratégico de órgãos e entidades envolvidos com o tema de TRPP, como também considera, em um ambiente organizacional turbulento, o aspecto temporal dos eventos, as ações de cada ator em seu ambiente e o tipo de intervenção requerido. Além disso, o modelo tanto pode ser empregado por um embarcador quanto por um grupo de embarcadores (por exemplo: em uma associação de fabricantes de determinado tipo de produto perigoso) e pode ser usado para qualquer Classe de Risco do produto transportado.

Com o intento de registrar uma possível aplicação do modelo proposto, discorre-se sobre o caso da logística reversa das embalagens vazias de agrotóxicos no TRPP, que foi sensivelmente modificada pelo estabelecimento de marco regulatório, um fator causador de elevada turbulência no setor regulado.

Segundo Leite (2003), várias são as razões ao estímulo à logística reversa: (i) sensibilidade ecológica; (ii) pressões legais, como marcos regulatórios; (iii) redução do ciclo de vida dos produtos; (iv) redução de custos; e (v) competitividade. Ou seja, ingredientes semelhantes aos atributos de Ansoff e McDonnell para análise da turbulência ambiental.

Conforme a Lei no 7.802/89 (ANVISA, 2011), agrotóxicos são produtos químicos destinados ao uso nos setores de produção, no armazenamento e beneficiamento de produtos agrícolas, nas pastagens, na proteção de florestas nativas ou implantadas, além de outros ecossistemas e também de ambientes urbanos, hídricos e industriais, cuja finalidade seja alterar a composição da flora ou da fauna, a fim de preservá-las da ação danosa de seres vivos considerados nocivos, bem como as substâncias e produtos empregados, como desfolhantes, dessecantes, estimuladores e inibidores de crescimento.

Sato et al. (2006) observam que o Brasil é um país de grande extensão de áreas agrícolas e que seu consumo de agrotóxicos é bastante elevado, gerando quantidade significativa de embalagens utilizadas e, por conseguinte, a serem retornadas e recicladas. Na safra de 2000/2001, foram utilizadas no campo 130 milhões de embalagens de agrotóxicos. $\mathrm{Na}$ safra de 2001/2002, o consumo de agrotóxicos 
FIGURA 5

Modelo proposto para planejamento de sistemas de informação como fator redutor de riscos no TRPP

Modelo de Araújo Jr. e Alvares (2007)

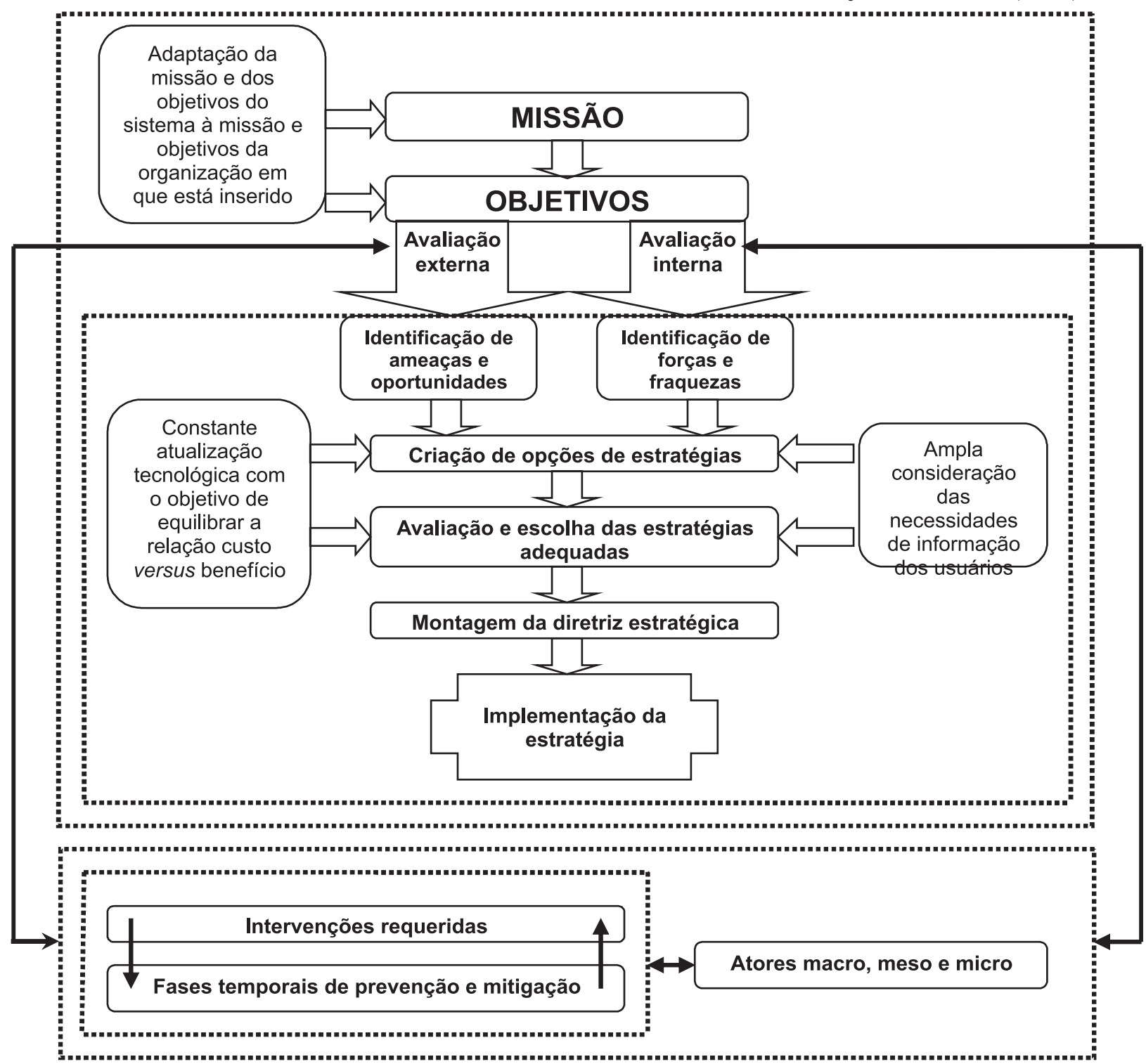

Modelo adaptado e reduzido de blocos de Andersson e Menckel (1995)

Fonte: adaptado de Araújo Jr. e Alvares (2007) e Andersson e Menckel (1995).

atingiu a quantidade de 32 mil toneladas (INPEV, 2011). Grande parte dessas embalagens teve destino desconhecido.

Os problemas ambientais causados por essas embalagens têm sido estudados por várias organizações governamentais e não governamentais. Expressiva maioria de autores desse campo de conhecimento trabalha com o conceito do "desenvolvimento sustentável", isto é, satisfazer às necessidades presentes sem comprometer a capacidade das gerações futuras de satisfazerem 
Proposta de modelo para planejamento de sistemas de informação para operação em ambientes de elevada turbulência...

as próprias necessidades (SATO et al., 2006). E, na direção da preservação do meio ambiente, o Brasil promulgou, em junho de 2001, o principal marco regulatório no que tange à logística reversa de embalagens vazias de agrotóxicos, consubstanciada na Lei no 9.974/00 e complementada pelo Decreto-Lei 4.074/02, que entrou em vigor em 2002, regulamentando, entre outras atividades, $\mathrm{o}$ transporte e a destinação final das embalagens vazias.

Em dezembro de 2001, foi criado o Instituto Nacional de Processamento de Embalagens Vazias (Inpev), que surgiu de iniciativa da indústria para atender às responsabilidades legais, sociais e ambientais no que se refere à destinação final das embalagens dos agrotóxicos comercializados.

Para planejar toda a rede e realizar a contratação de transporte para devolução das embalagens ao destino final, o Inpev criou o Centro de Programação de Transporte (CPT), dentro de seu departamento de logística e, como gestor de toda a rede, capacitou empresas de transportes locais, regionais e nacionais para cuidar da movimentação dessas cargas (capacitação tecnológica). Dessa forma, toda a cadeia logística teve que ser adaptada, desde o fabricante do agrotóxico até o consumidor final, valendo-se, entre outros, dos seus recursos produtivos não utilizados ou resíduos para cumprir os novos ditames legais.

Cabe destacar a criação de Procedimentos Operacionais Padrão (POPs) para as unidades de recebimento - uma das formas das rotinas de Nelson e Winter (2005) - que apresentam o conjunto de práticas indispensáveis ao seu funcionamento: desde como fazer a abertura das embalagens de agrotóxicos, até a elaboração de planos de ação preventiva e de controle de possíveis acidentes, resultando profundas modificações nos sistemas de informações e no consequente alinhamento estratégico das organizações envolvidas.

Verificou-se que, com a instalação do marco regulatório e com a adoção de sistema de informação adaptados à realidade de um meio turbulento, a relação entre a quantidade total de embalagens que tiveram correta destinação final $(\mathrm{t})$ e o total da safra agrícola de grãos (1.000t) era de 0,04 em 2002 e, em 2008, passou para 0,17; ou seja, um acréscimo de $335,30 \%$ no período considerado.

Assim, o que dantes era lixo rural, que contaminava o meio ambiente, passou a ser, após a reciclagem, mercadoria útil, na forma de tubos para fibra ótica, recipientes plásticos para lubrificantes e até mesmo de nova embalagem para defensivo agrícola.

Tomando por base as trajetórias tecnológicas propaladas por Dosi (2006), pode-se dizer que o Inper inovou o seu processo, como, por exemplo, com o uso de um triturador de embalagens vazias especialmente projetado. O sistema é composto por unidade móvel com capacidade para processar cinco toneladas de embalagens vazias por dia. Isso permitiu que o volume dos recipientes fosse reduzido em quatro vezes; os custos relacionados ao destino final e ao frete apresentaram economia significativa; o espaço destinado ao armazenamento da área segregada destinada a embalagens não laváveis foi otimizado; houve a economia de mais de 1.500 big bags (embalagens de resgate utilizadas para o transporte de recipientes não laváveis) desde o seu emprego em 2003; e utiliza número menor de unidades de transporte rodoviárias para realizar a movimentação de carga.

Além disso, os controles mais rígidos dos fluxos logísticos reversos de embalagens vazias que contiveram produtos perigosos, com base em novos sistemas de informação alinhados à nova estratégia organizacional, permitiram uma retroalimentação nos marcos regulatórios de transporte, em que se citam os novos conceitos aplicados para embalagens reutilizáveis (para o mesmo produto dentro do mesmo processo), recondicionadas e refabricadas, sendo que as duas últimas espécies necessitam de uma certificação compulsória por parte do Instituto Nacional der Metrologia, Normalização e Qualidade Industrial (Inmetro). 
CONCLUSÕES E RECOMENDAÇÕES FINAIS

O presente trabalho procurou definir um modelo para planejamento de sistemas de informação para operação em ambientes de elevada turbulência organizacional, exemplificando-o para o caso do transporte rodoviário de produtos perigosos, de modo que possa ser utilizado como uma ferramenta de redução de riscos de ocorrências indesejáveis na movimentação desse tipo de carga.

O modelo proposto contempla, concomitantemente, os benefícios do modelo para planejamento de sistemas de informação de Araújo Jr. e Alvares (2007) e as prerrogativas do modelo de prevenção de acidentes de Andersson e Menckel (1995), gerando uma ferramenta adequada para uso dos tomadores de decisão em ambientes turbulentos.

Como vantagens do modelo proposto, podem ser citadas: a estruturação dos sistemas de informação alinhados com o planejamento estratégico dos órgãos e entidades concernentes ao TRPP, em uma ambiência organizacional turbulenta, considerando, em seu bojo, os aspectos temporais dos eventos associados a riscos, as ações de cada ator em seu ambiente, o tipo de intervenção requerido e os fluxos informacionais, independentemente da Classe de Risco do produto perigoso.

Com a aplicação desse modelo, espera-se garantir que as informações estejam organizadas e utilmente sistematizadas aos atores correlatos com a cadeia logística de produtos perigosos, no tempo e nos locais certos para serem utilizadas, gerando não apenas ambientes de tráfego mais seguros e eficientes, como também prevenindo danos irrecuperáveis ao meio ambiente e à saúde da comunidade por onde transitam as unidades de transporte.

Para estudos futuros, sugere-se a aplicação do modelo para outros ambientes de elevada turbulência, como sistemas de defesa civil regionais. Assim como, no âmbito do TRPP, a modelagem de um sistema integrado georreferenciado de informações sobre os principais fluxos de tráfego rodoviário envolvendo produtos perigosos; estatísticas relativas aos acidentes ambientais; e substâncias químicas, recursos humanos e materiais mobilizáveis, capaz de fornecer o suporte necessário às equipes de atendimento emergencial em acidentes.

Artigo submetido em 10/07/2009 e aceito em 22/02/2011.

\section{REFERÊNCIAS}

ANDERSSON, R. e MENCKEL, E. On The Prevention of Accidents and Injuries - A Comparative Analysis of Conceptual Frameworks. Accidents Analysis and Prevention, New York, AAP, v. 27, n-6, p. 757-768, 1995.

ANSOFF, I. H. Strategic management. London: MacMillan, 1978.

ANSOFF, I. H. e McDONNELL, E. J. Implantando a administração estratégica. São Paulo: Atlas, 1993.

ANTT. Disponível em: <http://www.antt.gov.br >. Acesso em: 28 maio 2009.

ANVISA. Disponível em: < http://www.anvisa.gov.br $>$ Acesso em: 07 fev. 2011.

ARAÚJO JUNIOR., R. H. de; ALVARES, L. Planejamento de sistemas de informação: aspectos teóricos e elementos essenciais da estratégia e da implantação. In: ENCONTRO NACIONAL DE PESQUISA EM CIÊNCIA DA INFORMAÇÃO, 8., 2007, Salvador. Anais... Salvador, 2007.

BALLOU, R. H. Gerenciamento da cadeia de suprimentos / logística empresarial. Porto Alegre: Bookman, 2006.

BIO, P. R. Sistemas de informação: um enfoque gerencial. Rio de Janeiro: Atlas, 1989.

CERTO, S. C.; PETER, J. P. Administração estratégica. São Paulo: Makron, 1993.

CETESB. Relatório de emergências químicas atendidas pela CETESB em 2007. São Paulo: Companhia de Tecnologia de Saneamento Ambiental do Estado de São Paulo, 2008.

CHAÍN, C. N. Gestión de información en las organizaciones. Murcia: Universidad de Murcia, 2000.

DAVIS, G. B. Management information systems: conceptual foundations, structure and development. Tokyo: McGraw-Hill, 1974.

DOSI, G. Mudança técnica e transformação industrial. Campinas: Ed. Unicamp, 2006.

FURLAN, José D. Como elaborar e implementar planejamento estratégico de sistemas de informação. São Paulo: Makron Books, 1991. 
Proposta de modelo para planejamento de sistemas de informação para operação em ambientes de elevada turbulência...

GHEORGHE, A. V. Systems enginnering approach to risk and vulnerability management of transport dangerous goods. Zurique: Instituto Federal de Tecnologia, 2006.

HARTMAN, L. C. Uma metodologia para avaliação do risco do transporte de produtos perigosos por meio rodoviário. 2003. Dissertação (Mestrado em Engenharia Civil)-Faculdade de Engenharia Civil, Campinas, Unicamp, 2003.

HARWOOD, W. D., VINER, G. J.; RUSSEL, R. E. Characteristics of accidents and incidents. Transportation Research Record, Washington, TRB, n. 1245, pp. 23-33, 1989.

INPEV. Disponível em: <http:// www.inpev.org.br > Acesso em: 07 fev. 2011.

LEITE, P. R. Logística reversa: meio ambiente e competitividade. Prentice Hall: São Paulo, 2003.

LIEGGIO JÚNIOR, M. Transporte rodoviário de produtos perigosos: proposta de metodologia para escolha de empresas de transporte com enfoque em gerenciamento de riscos. 2008. Dissertação (Mestrado em Transportes), Universidade de Brasília, Brasília, 2008.

NELSON, R. R.; WINTER, S. G. Uma teoria evolucionária da mudança econômica. Campinas: Ed. Unicamp, 2005.

O'BRIEN, J. A. Introduction to information systems. 9. ed. New York: Irwin McGraw-Hill, 2000.

OLIVEIRA, D. P. R. de. Planejamento estratégico: conceitos, metodologia e práticas. São Paulo: Atlas, 1999.

OLIVEIRA, D. P. R. de. Planejamento estratégico: conceitos, metodologia e práticas. São Paulo: Atlas, 2001.

PIJAWKA, K. D.; FOOTE, S.; SOELSILO, A. Risk assesment of transporting hazardous material: route analysis and hazard management. Transport Research Record, Washington, TRB, n. 1020, pp. 01-06, 1985 .

POFFO, I. R. F.; GOUVEIA, J. L. N.; e HADDAD, E. Acidentes Ambientais e Comunicação de Riscos. In: CONGRESSO BRASILEIRO DE COMUNICAÇÃO AMBIENTAL, 2., 2005, Sâo Paulo. Anais... São Paulo: Revista Meio Ambiente Industrial, 2005.
PORATH, R., Costa; F. J. B., SILVA; V. A., MELLO, M. A. S; BICCA, V. H. F.; NASCIMENTO, S. N. Modelo de Análise de Risco para Classificação da Periculosidade de Rotas de Transporte de Produtos Perigosos com Uso de Procedimentos de MCDA. In: ENCONTRO NACIONAL DE CONSERVAÇÃO RODOVIÁRIA, 10., 2005, Joinville. Anais... Joinville: ENCOR, 2005.

RAMOS, F. B. Metodologia para escolha de alternativas de rotas para o transporte de materiais perigosos. 1997. Dissertação (Mestrado)-Escola de Engenharia de Produção, Florianópolis, 1997.

REAL, M. V. A Informação como fator de controle de riscos no transporte rodoviário de produtos perigosos. 2000. Dissertação (Mestrado)Universidade Federal do Rio de Janeiro, Rio de Janeiro, 2000.

REZENDE, D. A. Metodologia para projeto de planejamento estratégico de informações alinhado ao planejamento estratégico: a experiência do Senac-PR. Brasília: Ciência da Informação, v.32, n.3, p.146-155, set./dez. 2003.

RHYNE, R. W. Hazardous materials transportation risk: quantitative approaches for truck and train. New York: Van Nostrand Reinhold, 1994.

SANCHES, O. M. Planejamento estratégico de sistemas de informação gerencial. Revista de Administração Pública, agosto. Rio de Janeiro: FGV, 1997.

SATO, G. S.; CARBONE, G. T.; MOORI, R. G. Práticas Operacionais da Logística Reversa de Embalagens de Agrotóxicos no Brasil. Revista de Gestão Integrada em Saúde do Trabalho e Meio Ambiente, São Paulo, Intefarcehs, 2006.

SCALON, D. R.; CANTILLI, J. E. Assessing the risk and safety in the transportation of hazardous materials. Transportation Research Board, Washington, TRB, n. 1020, pp. 06-11, 1985.

VERTER, V. e KARA, B. Y. A GIS-Based framework for hazardous materials transport risk assessment. Risk. Analysis, EUA, v. 21, n. 6, pp. 1109-1120, 2001. 